\title{
NCI CTEP SDC Non-Small Cell Lung Cancer Sub-Category Terminology
}

National Cancer Institute

\section{Source}

National Cancer Institute. NCI CT EP SDC Non-Small Cell Lung Cancer Sub-Category

Terminology. NCI Thesaurus. Code C103090.

Non-Small Cell Lung Cancer is an NCI Cancer Therapeutic Evaluation Program (CTEP) Simplified Disease Classification (SDC) category used to organize cancer-related disease coding that harmonizes with and supports reporting based on the global standard Medical Dictionary for Drug Regulatory Reporting (MedDRA) terminology. 